\title{
A FORMAÇÃO DO DOCENTE PARA OS ANOS PRIMÁRIOS EM CURSOS UNIVERSITÁRIOS NO BRASIL E NA ALEMANHA
}

\author{
CATIA PICCOLO VIERO DEVECHI ${ }^{1}$ \\ https://orcid.org/0000-0002-5147-1609 \\ RALPH INGS BANNELL ${ }^{2}$ \\ https://orcid.org/ 0000-0001-8810-3490 \\ AMARILDO LUIZ TREVISAN ${ }^{3}$ \\ https://orcid.org/0000-0002-3575-4369
}

\begin{abstract}
RESUMO: O artigo discute a formação do professor dos anos primários, a partir de experiências em universidades públicas, no Brasil e no estado de Norte de Vestfália, na Alemanha. Procuramos compreender a articulação entre a formação social, cultural e humana e a formação técnica e especializada do professor dessa etapa de ensino nessas universidades. Sustentada na abordagem da hermenêutica reconstrutiva, a pesquisa, realizada em 2017, desenvolve-se por meio da comparação dos cursos de formação de professores nos dois países e utiliza-se da análise documental das diretrizes legais e das propostas pedagógicas de quatro cursos de formação de professores para os anos primários (dois brasileiros e dois alemães), além de entrevistas narrativas com especialistas brasileiros e alemães das mesmas instituições. A pesquisa indica que, independente do fato de ambas as universidades terem o mesmo interesse na qualidade da profissionalização técnica, nos cursos analisados da Alemanha, essa formação recebe mais ênfase do que no Brasil. Isso reflete os imperativos econômicos que norteiam a educação naquele país e, consequentemente, a necessidade de formação técnica. Contudo, nos cursos brasileiros aos quais tivemos acesso, ganha destaque o espaço de reprodução do mundo da vida e crítica ao sistema, indispensável a uma vida mais humanizada.
\end{abstract}

Palavras-chave: Formação docente, anos primários, Hermenêutica Reconstrutiva, mundo da vida.

\section{TEACHER TRAINING FOR PRIMARY SCHOOL IN UNIVERSITY COURSES IN BRAZIL AND GERMANY}

\begin{abstract}
The article discusses the teacher training for primary school based on experience in public universities in Brazil and in the state of North Westphalia in Germany. We seek to understand the articulation between social, cultural and human education and the technical and specialized training of teachers for this educational stage in these universities and countries. Based on a reconstructive hermeneutical approach, the research, carried out in 2017, was conducted through the comparison

\footnotetext{
${ }^{1}$ Universidade de Brasília (UnB). Brasília, DF, Brasil. <catiaviero@gmail.com>

2 Pontifícia Universidade Católica do Rio de Janeiro (PUCRJ). Rio de Janeiro, RJ, Brasil. < ralph@puc-rio.br>

${ }^{3}$ Universidade Federal de Santa Maria (UGSM). Santa Maria, RS, Brasil < amarildo1.trevisan@gmail.com> 
between teacher training courses in both countries, based on documental analysis of the legal guidelines and the pedagogical proposals for four teacher training courses for primary school (two Brazilian and two German), as well as narrative interviews with Brazilian and German specialists from the same institutions. The research indicates that, regardless of the fact that both universities have equal interest in the quality of technical professionalization, in the courses analyzed in Germany this specialized training is given more emphasis there than in Brazil. This reflects the economic imperatives that guide education in that country and the consequent need for technical training. However, regarding the Brazilian courses to which we had access, space for life-world reproduction and criticism of the system, indispensable for a more humanized life, emerges more prominently.

Keywords: Teacher training, primary school, Reconstructive Hermeneutics, life-world.

\section{FORMACIÓN DOCENTE PARA LA EDUCACIÓN PRIMARIA EN LAS CARRERAS UNIVERSITARIAS EN BRASIL Y ALEMANIA}

RESUMEN: El artículo discute la formación del profesor en la educación primaria, a partir de las experiencias obtenidas en las universidades públicas de Brasil y las del estado norte de Westfalia en Alemania. Buscamos entender la articulación entre la formación social, cultural y humana, con la formación técnica y especializada del maestro en este nivel de enseñanza en esas universidades. La investigación se sustentó sobre la base del enfoque de la hermenéutica reconstructiva, la cual se llevó a cabo en el 2017, y se desarrolló comparando las carreras de formación de profesores en ambos países, utilizando el análisis documental de directrices legales y propuestas pedagógicas de cuatro carreras de formación del profesor en la educación primaria (dos brasileñas y dos alemanas), así como entrevistas narrativas con especialistas brasileños y alemanes de las mismas instituciones. La investigación señaló que, a pesar de seguir el mismo interés en la calidad de la profesionalización técnica, en las carreras analizadas en Alemania, esta formación recibe más énfasis que en Brasil. Esto refleja los imperativos económicos que orientan la educación en ese país y en consecuencia la necesidad de formación técnica. Sin embargo, en las carreras brasileñas a los que tuvimos acceso, se destaca el espacio para la reproducción del mundo de la vida y la crítica del sistema, indispensable para una vida más humanizada.

Palabras clave: Formación docente, Educación primaria, Hermenéutica reconstructiva, mundo de la vida.

\section{INTRODUÇÃO}

Neste artigo, buscamos discutir como tem se dado a articulação entre a formação social, cultural e humana e a formação técnica e especializada do professor do anos primários, em universidades brasileiras e alemãs. Para tanto, utilizamos alguns dados alcançados, numa pesquisa comparada, realizada em 2017, sustentada na hermenêutica reconstrutiva, de cursos que formam professores para essa etapa de ensino, em universidades nos dois países. A investigação foi efetivada em dois cursos de pedagogia, em universidades públicas brasileiras e dois cursos de formação de professores para os anos primários, em duas universidades públicas no Estado da Renânia do NorteVestfália (Nordrhein-Westfalen - NRW) na Alemanha e, para isso, realizamos a análise documental e entrevistas narrativas com especialistas das instituições. ${ }^{4}$ Em ambos os países, os cursos precisaram se

\footnotetext{
${ }^{4} \mathrm{O}$ projeto de pesquisa visava conhecer as concepções pedagógicas, a estrutura dos cursos e as formas de organização de ensino, pesquisa e extensão de Faculdades, Institutos ou Departamentos de Educação, no Brasil (após a Resolução CNE/CP n. 1/2006) e, na Alemanha (após a Declaração de Bolonha/1999). Buscou discutir ainda as possibilidades de aprendizagem comunicativa sobre a formação do pedagogo entre os dois países. A visita às duas universidades alemãs, e consequente realização, transcrição e tradução de entrevistas e de outros documentos, foi financiada com recursos do Edital Universal do Conselho Nacional de Desenvolvimento Científico e Tecnológico (CNPq) 14/2014 (Processo N. Educação em Revista|Belo Horizonte|v.36|e231370|2020
} 
adaptar a novas diretrizes curriculares para a formação desses professores. No Brasil, os cursos de pedagogia ajustaram-se às exigências da formação inicial para o exercício da docência, na educação infantil e nos anos primários do ensino fundamental e de outras modalidades de atuação pedagógica (BRASIL, 2006). Na Alemanha, os cursos procuraram atender aos padrões de formação referentes às competências, habilidades e atitudes entendidas como necessárias ao exercício da profissão docente (KMK, 2004).

No sentido de permitir a compreensão de tais adaptações, procuramos explicitar, ao longo do texto, a análise dos documentos que descrevem a forma de organização, o enfoque dos cursos e as interpretações de documentos norteadores. Dessa forma, tal análise partiu das Diretrizes Curriculares Nacionais para o Curso de Pedagogia, no Brasil (DCNP) e, na Alemanha, analisamos a KMK/2004, sobre a formação do docente para os anos primários, e também as Diretrizes da Formação Docente (NRW/Lehrerausbildungsgesetz - LABG ), as quais entraram em vigor, no dia 26 de maio de 2009, cuja última revisão ocorreu, em 14 de junho de 2016, pelo Decreto de Acesso ao Exercício da Docência (NRW/ Lehramtsæugangsverordnung - LZV/2016). Tal análise documental é articulada com as análises dos resultados das entrevistas narrativas com especialistas realizadas com coordenadoras dos cursos de pedagogia no Brasil, professores dos Institutos de Ciências da Educação e coordenadores dos Centros de Formação Docente (Zentrum für Lebrerbildung - ZLB) na Alemanha. ${ }^{5}$

No Brasil, analisamos os documentos legais orientadores da formação dos professores de anos iniciais (LDB/1996, DNCP/2006, DCN/2015), os dados dos projetos pedagógicos de dois cursos de pedagogia de Universidades Federais, recentemente, reformulados, e os relatos de duas entrevistas narrativas individuais realizadas com coordenadoras desses cursos e, portanto, participantes do Núcleo de Docente Estruturante (NDE), identificadas, no texto, pelas letras EA e EB. As entrevistas seguiram um roteiro prévio com 10 questões que trataram, principalmente, sobre a adaptação dos cursos em relação às orientações das DCN, sobre os espaços de autonomia dos cursos e sobre o lugar dos fundamentos da educação na formação dos professores. Cada entrevista teve duração média de 1 hora e 30 minutos, somando, aproximadamente, 3 horas de gravação.

$\mathrm{Na}$ Alemanha, a pesquisa desenvolveu-se, a partir da análise documental das diretrizes legais que regem a formação de professores, no estado da Renânia do Norte-Vestfália (NordrheinWestfalen - NRW) e partiu também das propostas pedagógicas referentes às ciências da formação de dois de seus cursos de universitários e de quatro entrevistas narrativas com seis especialistas (WELLER; ZARDO, 2013). As entrevistas foram realizadas com coordenadores dos Centros de Formação Docente (ZLB) e professores do Instituto de Educação da Westfälische Wilhelms-Universität Münster (WWU-Münster) e do Instituto de Pedagogia da Universität Duisburg-Essen (UDE), com um total de seis participantes já que, em uma das universidades, duas entrevistas ocorreram em dupla por opção dos professores previamente contatados. Os entrevistados estão caracterizados da seguinte forma: EM1, EF1 e EF2, professores do Institutos de Ciências da Educação, e BM1, BM2 e BM3, coordenadores dos ZLBs, sendo que M e F marcam o gênero dos participantes, indicando masculino e feminino.

Para a realização das entrevistas, estabelecemos um roteiro prévio com dez questões que trataram, principalmente, sobre a adaptação dos cursos em relação às orientações do processo de

455699/2014-3). Registramos nossos agradecimentos ao CNPq, aos professores Nicolle Pfaff (UDE) e Marcelo Amaral (WWU) pelo auxílio na organização dos contatos com os entrevistados, bem como pelo acolhimento, durante a estada na Alemanha, pela colaboração da Professora Wivian Weller (PPGE/UnB), durante a realização das entrevistas e nas reflexões presentes no artigo, auxílio da Profa. Benedetta Bisol (PPGE/UnB) na tradução dos textos e da Profa. Evanir Piccolo Carvalho (IFFar) na revisão textual do artigo.

${ }^{5}$ Os cursos contam com o apoio do Centro de Formação de Docentes (ZLB - Zentrum für Lehrerbildung), que é uma unidade independente na universidade responsável pelo incentivo interdisciplinar/transdisciplinar da formação acadêmica dos docentes e aconselhamento da reitoria sobre todas as questões nesse domínio. Trata-se de uma unidade universitária com servidores e apoio do ministério da educação. Os objetivos dos centros (ZLB) residem nas áreas de aconselhamento do aluno e coordenação do curso, fases práticas, assim como pesquisa, aplicação dos saberes e aperfeiçoamento. A proposta é que os centros fortaleçam a formação nas 26 disciplinas que serão ensinadas nas escolas, suas didáticas e avaliações específicas, assim como as ciências da formação na universidade. Além disso, os ZLB atuam na mediação entre a universidade, as escolas e os respectivos órgãos públicos, bem como no estabelecimento de redes e canais de comunicação com as escolas. Para informações sobre os ZLB, cf. Merkens (2005) e Hilligus (2015).

Educação em Revista|Belo Horizonte|v.36|e231370|2020 
Bolonha e da LABG, os espaços de autonomia dos cursos e o surgimento da área de Ciências da Formação. As entrevistas tiveram duração média de 1 hora e 30 minutos cada, somando, aproximadamente, 6 horas de gravação.

Compreendida a forma de organização e o enfoque dos cursos por meio da análise dos documentos e das entrevistas narrativas nos dois países, discutimos os dados a partir da Teoria da Ação Comunicativa do filósofo Jürgen Habermas (2012). Nessa teoria, a realidade social reproduz-se em dois níveis - o sistêmico e o mundo da vida. O mundo da vida é a esfera de reprodução da sociedade que inclui o saber cultural, as normas sociais e as estruturas da personalidade dos indivíduos inseridos nela. O sistema (dividido em econômico e administrativo, relacionado às instituições e a estruturas políticas) é a esfera da sociedade onde a reprodução social acontece pela via dos mecanismos de poder e dinheiro. Assim, Habermas desenvolve uma análise da diferenciação da sociedade que ajuda explicar a racionalização da sociedade em duas dimensões: uma mediada linguisticamente e guiada pelas normas sociais e pelo saber cultural; outra mediada por dinheiro e poder. Portanto, a racionalização da sociedade que se deu por meio da racionalização da ética e da cultura, é responsável pela formação da identidade do Eu e da personalidade, bem como pela (re)produção do saber cultural e das normas sociais de uma sociedade. Tal processo resultou de uma racionalização das estruturas econômicas e políticas de poder que levaram a um desencantamento do mundo e ao desenvolvimento de estruturas econômicas e políticas necessárias para sociedades complexas.

A racionalização, em ambas as esferas, opera via atos comunicativos, estratégicos no caso dos subsistemas e comunicativos no caso do mundo da vida. A ação comunicativa, por sua vez, tem uma forma normal, responsável pela reprodução da sociedade, e uma forma "reflexiva", responsável pela possibilidade de crítica, contestação e, eventualmente, emancipação. A ação comunicativa tem, portanto, uma potencialidade para a racionalidade não contida na ação estratégica, necessária para a reprodução dos sistemas administrativos e econômicos da sociedade. (BANNELL, 2013)

O diagnóstico central de Habermas é o de que os subsistemas têm colonizado o mundo da vida, resultando em uma perda dos recursos necessários para a sua reprodução - especialmente, a racionalidade comunicativa e, consequentemente, a socialização e a individuação do sujeito. A partir dessa teoria, poderíamos conceber a tarefa da educação como sendo a de articular a formação diante dos desafios impostos pelo desacoplamento dessas duas dimensões da racionalidade moderna: a articulação da formação técnica (necessária ao sistema) com a formação humanística (demandas do mundo da vida). Para o autor, os processos de aprendizagem são desafiados a enfrentar a pluralidade das demandas científicas, as interações com a economia e a administração, como também as funções de reprodução da vida. A preparação para a carreira acadêmica envolve, assim, contribuir para o processo de socialização, para além do saber especializado, colaborar para a formação crítica do intelectual, com leituras fundamentadas dos acontecimentos atuais, e a tomada de posição política. A reflexão sobre os métodos e fundamentos auxilia as ciências humanas na continuidade da hermenêutica das tradições, com as teorias da ciência, da moral, da arte e da literatura, para a formação de uma consciência própria das ciências no âmbito geral da cultura (HABERMAS, 1993). Trata-se de um desafio de redefinição da Bildung clássica (formação cultural), diante das demandas educacionais atuais.

É importante destacar que, na teoria de Habermas, a força reflexiva da ação comunicativa, é expressa nos discursos (teórico, voltado a refletir sobre questões científicas, e prático, voltado às questões práticas, morais, éticas, políticas, jurídicas, etc.), não está eclipsada nas sociedades contemporâneas, embora ameaçada pela colonização do mundo da vida pelos subsistemas. A universidade, portanto, deveria ser um lugar privilegiado, segundo Habermas (1993), para o desenvolvimento de tais discursos, que despertam, por sua vez, processos de aprendizagem nas dimensões técnico-científicos, orientadas aos subsistemas, como na dimensão prática, orientada ao mundo da vida. Em uma intervenção, na sociedade alemã, em 1979 (HABERMAS, 1979), o autor advertiu sobre o perigo enfrentado pela sociedade alemã, na época, quando o espaço para reflexão e discurso crítico foi reduzido pelos imperativos do mercado, especialmente nas universidades.

Habermas (1993) aponta a comunicação, especialmente, a ação comunicativa, como possibilidade integradora da universidade e, mais do que isso, ela é a garantia do espaço democrático para o surgimento de um "argumento surpreendente" (p. 129), ou seja, a possibilidade de uma forma 
reflexiva da ação comunicativa produzir um novo olhar a um tema colocado em discussão. São as formas comunicativas da argumentação científica, moral e jurídica que, segundo ele, permitem dar coesão e unidade aos processos de aprendizagem universitária nas suas diversas funções. Segundo Oliveira (2002, p. 113),

A ideia habermasiana de universidade visa resgatar uma concepção comunicativa de educação que seria ameaçada por um reducionismo técnico-científico segundo o qual as mais diversas áreas específicas do saber se propõem a oferecer novas tecnologias e potenciais soluções para os problemas da humanidade.

A universidade deve ter como projeto a cooperação a partir do alicerce do mundo da vida. As disciplinas científicas, na sua diversificação, constituem-se em espaços públicos internos que surgem em conjunto e voltam a se dispersar nas atividades públicas da universidade. Os próprios seminários e a cooperação científica são de caráter público. Os processos universitários de aprendizagem garantem, assim, que as portas permaneçam abertas, afinal "a cada momento pode surgir um novo rosto e uma ideia inesperada" (HABERMAS, 1993, p. 129).

A abordagem da hermenêutica reconstrutiva (DEVECHI; TREVISAN, 2010), operada a partir da teoria da ação comunicativa de Habermas, coloca-se contra o historicismo, corrente já fortemente combatida pela epistemologia contemporânea. Dessa forma, a história não é vista como socialmente determinante, mas como um movimento orientado por meio do aprendizado comunicativo que a própria história torna possível. Para tal hermenêutica, interessa não apenas a relação ator e contexto, mas o nexo causal dessa relação no que diz respeito à importância da linguagem ou da comunicação. É por intermédio do uso da linguagem em ação que os atores entendem-se sobre as demandas do mundo da vida, firmando acordos que permitem a funcionalidade de o sistema operar pela via simbólica do discurso. Habermas cultiva essa visão ao defender uma ampliação do diálogo com o outro como condição para a produção de significados, os quais são construídos e reconstruídos na relação entre sujeitos capazes de linguagem e ação. Há um descolamento do eixo de gravidade da discussão da história para o ângulo da compreensão dos processos sociais constituídos como sistemas normativos capazes de, ao abarcar os contextos específicos dos diversos intérpretes, revelar novas possibilidades críticas.

Entendemos a formação de professores como sendo o espaço propício para essa discussão, dado o seu compromisso histórico com o atendimento não a um discurso monológico e saturado, mas resguardando a pluralidade de perspectivas e seu consequente debate. Deveria ser um espaço de diálogo acadêmico e democrático, no qual o contraponto de ideias é necessário para o aperfeiçoamento e a confiabilidade das discussões. Visto que este trabalho não visa, em princípio, fazer uma análise comparativa ampla e irrestrita entre os dois países, mas apresentar a oportunidade de aprendizagens específicas abertas à experiência do outro e do diferente, não pretendemos generalizar a partir das experiências analisadas. No entanto, há compreensões que precisam ser expostas, embora colocadas no contexto social e cultural específico de cada país. Isso não significa que estamos fazendo comparações segundo a lógica do simples transplante cultural de realidade de um país para outro, levando a formação a ocorrer de maneira descontextualizada. Para isso, nos apoiamos em publicação, no campo da educação comparada, quando aduz, a esse respeito, que

os desafios atuais da educação comparada colocam-se principalmente no campo da percepção do outro e de suas diferenças culturais e imaginárias como um outro, e não idêntico a si mesmo. Não é mais pretensão da maioria dos estudos copiar modelos estrangeiros por meio da perspectiva histórica, como buscou Isaac Kandel (1933), nem oferecer um tratamento estatístico dos dados, como buscaram Noah e Eckstein (1969), mas construir outros significados e histórias por meio da multiplicidade dos campos discursivos. Não se intenciona produzir saberes generalizáveis e inabaláveis, mas interpretações comprometidas com a pluralidade de sentidos e seus respectivos contextos (DEVECHI, TAUCHEN; TREVISAN, 2018, p. 7) 
Estudos comparados constituem instrumentos analíticos de sistemas educativos que permitem ampliar o campo de compreensão da realidade nacional em face de outros países, particularmente, no campo das políticas públicas. No entanto, sobre os procedimentos empregados no presente estudo comparado, é preciso considerar que há condições teóricas e metodológicas específicas necessárias para a sua utilização. "Isso porque, não podendo mais compreender os processos educacionais por fatos objetivos, mas especialmente por meio da linguagem, tem-se no discurso a oportunidade de renovar os saberes da área pelas objeções dos outros interlocutores." (DEVECHI; TAUCHEN; TREVISAN, 2018, p. 11).

A investigação é entendida como qualitativa e, portanto, não tem como foco de preocupação a quantidade de unidades de investigação, mas, sim, o significado ou sentido da seleção que, no contexto, se articula com interpretações realizadas, no âmbito do grupo de pesquisa, acerca da legislação e com outras pesquisas as quais apontam para a mesma problemática. Contexto, nesse caso, "não deve ser definido como lugar ou localização, mas deve ser conceituado como algo espacial e relacional” (BARTLETT; VAVRUS, 2017, p. 915-916). É claro que as instituições investigadas não são representativas da heterogeneidade dos países e, portanto, os resultados do estudo apresentam limitações diante da complexidade da formação docente para os anos primários, no Brasil e na Alemanha.

Desse modo, o que buscamos é um estudo comparado (BARTLETT; VAVRUS, 2017) para refletir sobre o quanto duas realidades formativas específicas do Brasil e da Alemanha aproximamse ou distanciam-se, em suas singularidades, no tratamento da formação do professor dos anos primários e, assim, permitem que as instituições e/ou pessoas possam se beneficiar à sua maneira mediante processos de aprendizagem. Em relação ao curso de pedagogia, no Brasil, além de apresentar uma trajetória de tensões em relação a sua identidade, ele tem características muito peculiares em relação ao seu modelo de profissionalização. Trata-se de um curso com diferentes modalidades de atuação, e a formação para os anos primários é apenas uma delas. Percebemos como algo bem distinto da formação alemã que possui um curso de formação de professores focado, unicamente, na docência dos anos primários do ensino fundamental (DEVECHI; WELLER, 2018).

Nesse sentido, discutimos a respeito de como os cursos têm procurado se estruturar frente às demandas da formação para o trabalho com a formação simbólica responsável pela dimensão da cultura, da sociedade e da sobrevivência das tradições e das identidades. A temática desenvolvida tem relevância no que diz respeito a pensar a formação e a profissão docente, especialmente para os anos primários. Em especial, a perspectiva adotada busca compreender como se constituem as similaridades e/ou diferenças entre duas experiências de formação do Brasil e da Alemanha, seus contextos históricos e políticos específicos, e as reformas decorrentes para a área de formação de professores. Tratamos de debater o enfrentamento dos cursos de formação de professores para os anos primários na universidade, diante das demandas do sistema e da necessidade de comprometimento com a participação comunicativa e inclusão social.

O artigo se estrutura em três seções: a primeira apresenta a organização e o ponto de vista da formação do docente para os anos primários no Brasil (curso de pedagogia); a segunda explicita a forma de organização e o enfoque da formação docente para os anos primários, em cursos de universidades públicas, no estado de NRW, na Alemanha; e a terceira discute os modelos de formação docente para os anos primários, nas universidades investigadas, nos dois países no que se refere à articulação entre a formação técnica necessária às demandas do mercado e a formação integral articulada às necessidades do mundo da vida.

\section{FORMAÇÃO DOCENTE PARA OS ANOS PRIMÁRIOS: EXPERIÊNCIA EM UNIVERSIDADES BRASILEIRAS E ALEMÃS}

Atualmente, a formação universitária vem sendo sobrecarregada por uma tendência profissionalizante e técnica a qual desconsidera a aprendizagem articulada à formação humana, responsável pela dimensão social, cultural e da vida. Tanto a compreensão de Humboldt (apud 
Habermas, 1993) de que a universidade deveria apostar na unidade da ciência e do esclarecimento crítico, como as tentativas de atualização dessa ideia, parecem ter cedido o lugar para treinamento especializado de profissionais, para atenderem as demandas do mercado. Mesmo a preocupação com a formação reflexiva do aprendente ao longo da vida, como o enfoque concentrado em sujeitos que cooperam uns com os outros e sabem resolver problemas no coletivo, tem como direcionamento o atendimento a uma lógica neoliberal minimizadora do papel formativo. Essa inclinação é explicada por Nussbaum (2015), ao dizer que, para se manterem competitivos no mercado global, os países têm realizado mudanças radicais na educação e, para tanto eliminam as humanidades da formação dos sujeitos e simplificam o espaço construtivo, criativo e crítico, em favor do aperfeiçoamento das competências lucrativas.

Com relação à formação de professores do ensino básico, temos acompanhado orientações cada vez mais controladas que se referem à ampliação de determinadas competências profissionais e enxutas quanto às preocupações com a emancipação social e com a reprodução das tradições culturais. Gruschka (2015), por exemplo, pergunta se a pedagogia, na Alemanha, estaria suficientemente atrelada ao social de forma que fosse capaz de refletir sobre a educação e a formação ou se, com o triunfo do neoliberalismo, teria que atestar a colonização do pedagógico que se encontra, completamente, subsumido no interesse de produção da mão de obra? Segundo o autor, "as condições sob as quais a formação (Bildung) pode florescer estão minadas quase sistematicamente, tanto na escola como na universidade" (p. 276). Isso significa que a ideia de formação está, cada vez mais, contornada pela demandas do mundo regido pela economia em detrimento da formação da vida humana, na sua integralidade.

\section{Experiência de formação docente para os anos primários em universidades brasileiras}

No Brasil, a formação docente para os anos primários acontece no curso de pedagogia. O curso tem sido debatido de forma polêmica desde o seu surgimento, em 1939 (SAVIANI, 2012). Superada a fase de preocupação, em relação à priorização da formação dos professores de educação infantil e dos anos primários do ensino fundamental, nos Institutos Normais Superior, estabelecida pela Lei de Diretrizes e Bases da Educação (LDB) de 1996, outras questões passam a ser debatidas. Dúvidas que foram colocadas na sua trajetória histórica, desde o seu surgimento em 1939, como formação do docente, formação do especialista, profissionalização do pedagogo e identidade da pedagogia são reacendidas nas discussões. Entre 1962 e 1996, muitas discussões e propostas foram levantadas, visando à restruturação ou extinção do curso de pedagogia, tendo em vista a falta de identidade de seu saber (BRZEZINSKI, 2013). Atualmente, a pedagogia encontra-se vinculada, prioritariamente, à profissão docente com a preocupação voltada para a melhoria da escola básica e, quando possível, busca atender as demandas da formação para a gestão, em espaços escolares e não escolares.

O objetivo original, de 1939, do curso voltado à formação de especialistas da educação foi substituído pela formação de professores dos anos primários e da educação infantil com preparo para as atividades escolares de gestão, fato que não aconteceu imediatamente, mas foi firmando-se, lentamente, por meio de diversas discussões com representantes das mais distintas entidades do setor educacional, associações acadêmicas, prioritariamente, a Associação Nacional pela Formação dos Profissionais da Educação (Anfope), universidades e instituições superiores. Foram muitas décadas de discussão e tramitação, no Conselho Nacional de Educação (CNE), para chegar à compreensão de que o curso de pedagogia devia ter como prioridade a formação para a docência, conceito compreendido de forma ampliada no sentido de atender, além da tarefa de professor, a de pesquisador e de gestor de ambientes escolares e não escolares.

As Diretrizes Curriculares Nacionais para o Curso de Graduação em Pedagogia (DCNP) foram consolidadas, nos Pareceres CNE/CP n. 05/2005, CNE/CP n. 01/2006 e na Resolução CNE/CP n. 01/2006. Elas definiram os princípios, as áreas de atuação e a abrangência da formação em pedagogia e aplicam-se 
à formação inicial para o exercício da docência na educação infantil e nos anos iniciais do ensino fundamental, nos cursos de ensino médio, na modalidade normal, e em cursos de educação profissional na área de serviços e apoio escolar, bem como em outras áreas nas quais sejam previstos conhecimentos pedagógicos (BRASIL, 2006).

Em 2015, foi aprovada outra Resolução (n. 2) a qual instituiu as Diretrizes Curriculares Nacionais para a Formação Inicial, em Nível Superior (DCN/2015) que aumentaram as horas dedicadas ao estágio supervisionado, distribuindo-as, ao longo da graduação, na área de formação e atuação na educação básica. Tal aprovação deu-se diante de novas discussões e movimentos realizados em torno de questionamentos das diretrizes anteriores e da necessidade de articular o ensino superior e a escola básica. Além disso, somaram-se a esse contexto as metas do Plano Nacional de Educação (PNE) o qual busca melhoria da formação inicial e continuada de profissionais do magistério da educação básica.

O conhecimento acerca da complexidade da escola ganha ênfase, o que se confirma pelo aumento da quantidade de horas voltadas às atividades práticas. O objetivo geral de tal ampliação foi permitir ao futuro docente maior conhecimento sobre a escola e suas demandas práticas. Desse modo, com o foco na docência, o curso de pedagogia ficou mais próximo das demais licenciaturas, com a diferença de assumir o compromisso com a formação em todos os saberes específicos (matérias) necessários para a docência na educação infantil e anos iniciais do ensino fundamental, para formação do gestor escolar e não escolar e o cientista da educação.

No entanto, apesar das diretrizes terem resultado das discussões das mais atuantes entidades acadêmicas da área, não se tratou de uma perspectiva consensuada, tendo em vista a preocupação no que se refere à redução do objetivo do curso de pedagogia à prática docente (GARCIA, 2016), bem como o caráter generalista do curso (SAVIANI, 2012; FRANCO; LIBÂNEO; PIMENTA, 2007) e a fragilidade da formação para a atuação, nos anos primários e na educação infantil (GATTI, 2010).

Gatti (2010), por exemplo, pergunta se a formação do pedagogo está sendo suficiente para o futuro professor vir a planejar, ministrar e avaliar atividades de ensino para os anos primários do ensino fundamental e para a educação infantil. Saviani (2012, p. 58) manifesta críticas às DCNP, dizendo ser "ao mesmo tempo, extremamente restritas e demasiadamente extensivas: muito restritas no essencial e assaz excessivas no acessório", em relação à prática docente na escola. Já Franco, Libâneo e Pimenta (2007, p. 92) afirmam que o conceito de docência, presente nas diretrizes curriculares para a formação em pedagogia, caberia a especialistas como o "planejador da educação, o especialista em avaliação, o animador cultural, o pesquisador, o editor de livros, entre tantos outros". Os autores ressaltam que a formação do pedagogo

desprezou a epistemologia desse campo científico; desconsiderou as possibilidades e necessidades da formação desse profissional para atender às complexas demandas da escola brasileira e, ainda, não se apropriou dos saberes da prática pedagógica, construídos no seu caminhar histórico (FRANCO; LIBÂNEO; PIMENTA, 2007, p.91).

Essa formação expressa, segundo eles, uma "concepção simplista, reducionista da pedagogia e do exercício profissional do pedagogo, decorrente de precária fundamentação teórica, de imprecisões conceituais, de desconsideração dos vários âmbitos de atuação científica e profissional do campo educacional" (FRANCO; PIMENTA; LIBÂNEO, 2007, p. 94). Ou seja, a formação em pedagogia estaria fragmentada, em diversas funções profissionais e docentes e não consegue atender as demandas docentes da educação infantil e dos anos primários.

Diante da tendência mundial de formar o professor, a partir do paradigma das competências e das críticas da formação do professor no Brasil, foi aprovada, no âmbito de CNE, uma nova resolução CNE/CP $\mathrm{n}^{\circ}$ 2, de 20 de dezembro de 2019, que estabelece as novas Diretrizes Curriculares Nacionais e Base Nacional Comum para a Formação Inicial e Continuada de Professores da Educação Básica. O foco da proposta, fundamentada na abordagem da educação baseada em 
evidências, é o desenvolvimento das competências gerais dispostas na Base Nacional Comum Curricular. Segundo o que consta no documento: "A formação docente pressupõe o desenvolvimento, pelo licenciando, das competências gerais previstas na BNCC-Educação Básica, bem como das aprendizagens essenciais a serem garantidas aos estudantes, quanto aos aspectos intelectual, físico, cultural, social e emocional de sua formação" (BRASIL, 2019). Em relação ao curso de pedagogia, a proposta concentra-se especificamente no desenvolvimento das competências e habilidades profissionais (conteúdos de aprendizagem e didáticas de aprendizagem dos conteúdos) para a atuação docente na educação infantil e nos anos primários, e tal perspectiva exigirá um novo redirecionamento curricular do curso nos próximo anos.

\section{Organização atual dos cursos}

A partir da análise dos documentos legais e curriculares orientadores dos cursos, e das entrevistas realizadas, compreendermos não estar clara a definição do papel do profissional pedagogo, o que, segundo entrevistadas e especialistas da área (SAVIANI, 2012; LIBÂNEO, 2013), tem dado margem para várias interpretações, formas de atuação e de organização. Além disso, os cursos estão com dificuldades de atender à demanda da profissionalização, nas diferentes modalidades, conforme as orientações das DCNP. Há a oferta de uma formação geral com o eixo mais ou menos direcionado para docência nos anos primários, a qual se esforça para garantir a formação do professor da educação infantil e, ainda, busca diversificar os estudos para atender à demanda pedagógica de espaços pedagógicos não escolares.

O resultado tem sido uma formação mais generalista que oferece um conhecimento introdutório sobre a docência para os anos primários e algumas 'pinceladas' em relação a outras modalidades, conforme mostram as matrizes curriculares e as ementas analisadas. A entrevistada EA diz: "no fim das contas, esse profissional, até pelas características, pelo perfil socioeconômico do estudante de pedagogia, vai muito buscar o que o mercado está oferecendo". Isso justificaria o enfoque na formação para os anos primários e o não direcionamento para outras modalidades.

O contexto brasileiro, com sua enorme desigualdade social e econômica, bem como o desprezo para com a educação pela maioria dos governos Federais, Estaduais e Municipais, ao longo da história do país (com possível, exceção do primeiro década do século XXI, quando houve uma leve melhoria nesse cenário), pode parcialmente explicar esse viés no curso de Pedagogia. A maioria dos alunos desse curso é oriundo das classes populares, cuja prioridade é entrar no mercado de trabalho e ganhar a vida, numa posição superior a de seus familiares e de outras pessoas da mesma classe social. Esse desejo vai ao encontro dos imperativos do mercado e da necessidade de formação de mão de obra para a economia. Tal ideia faz pressão sobre os formuladores de políticas educacionais e cursos de formação para a organização de cursos orientados a esses imperativos.

Embora a formação para a docência na educação infantil apareça como um dos objetivos, nas diretrizes legais e nos projetos pedagógicos dos cursos, na prática, a prioridade é a formação do professor dos anos primários, conforme ressalta a entrevistada EB: é lógico que a gente vai olhar para educação infantil que tem uma relevância hoje muito grande,
uma importância, mas a gente vai ter os anos iniciais ou manter estes anos iniciais como foco.

Ao analisar o currículo dos cursos é possível identificar que as disciplinas específicas, para o ensino nos anos primários, ocupam uma parte maior da carga horária em relação às disciplinas de educação infantil. Mais um vez, o contexto brasileiro contribui para explicar essa ênfase, na medida em que os problemas na educação escolar dos anos primários permanecem grandes, se não no acesso à escola, certamente, na qualidade do ensino oferecido, focando atenção nessa etapa de ensino como base para as etapas posteriores. A educação infantil, embora ganhando espaço nos debates e políticas educacionais nas últimas décadas, exigiria um gasto de verbas públicas, para além do que a maioria dos governos estão dispostos a investir. É inevitável que esses imperativos econômicos e sociais 
influenciem não somente políticas públicas para a educação, mas também o conteúdo dos cursos de formação de professores.

Já em relação ao enfoque da pesquisa científica, há uma preocupação dos cursos investigados para que a formação esteja articulada com a pesquisa na pós-graduação. Além do professor o qual também deve ser gestor, os cursos têm procurado fazer uma iniciação da preparação do cientista da educação. Segundo as palavras da entrevistada EA, "se você pensar na pedagogia sendo licenciatura, eu acho que a pesquisa das práticas, das metodologias, das didáticas, elas hoje têm um peso incrível". $\mathrm{Na}$ verdade, os cursos têm se esforçado para salvaguardar, embora de forma secundária em relação às atividades de ensino, as perspectivas da investigação científica, um dos objetivos da formação universitária. Entretanto, diante do compromisso com a formação, em diferentes modalidades, os cursos estão distantes de conseguir desenvolver as competências necessárias para o estudante tornar-se um pesquisador, mesmo que iniciante, em educação.

Além disso, o interesse maior dos estudantes com o curso é conseguir um emprego, conforme enfatiza a entrevistada EA: "eles querem é mercado, é mercado de trabalho, as pessoas precisam trabalhar". Tal afirmação evidencia as necessidades de os cursos focarem em "mecanismos sistêmicos que se desprendem cada vez mais das estruturas sociais mediante as quais se realiza a integração social"' (HABERMAS, 2012, p. 278), pensamento muito desfavorável para um profissional dedicado à formação humana. Apesar de especialistas da área (GATTI, 2010; SAVIANI, 2012; LIBÂNEO, 2013) apontarem fragilidades na profissionalização do professor, há uma importante preocupação dos cursos com a empregabilidades dos estudantes. O cuidado com o mercado laboral sem dúvida é maior que a preocupação com as experiências de socialização cultural e a reprodução do mundo da vida, necessárias à cidadania, embora essas últimas ainda tenham um papel importante na formação conferida na universidade.

Dito isso, é importante notar que o conteúdo curricular voltado à socialização cultural e reprodução do mundo da vida está presente nos cursos examinados, nesta pesquisa. Em nossa opinião, o fato de ainda constar, na formação de docentes, reflete o contexto brasileiro, especialmente a luta entre um projeto social e político voltado ao mercado e outro voltado a uma sociedade que valoriza a igualdade econômica, pluralidade cultural e a cidadania inclusiva. Depois da redemocratização do país, no final da década de 80 , esses projetos encontraram-se em articulação, tanto na sociedade como na esfera política com seus reflexos em projetos para a educação (CUNHA, 1989, 1995, 2007). Nesse momento, o projeto voltado a uma formação humana e plena ganhou fôlego, com a incorporação de elementos dele nas propostas da formação de docentes.

No entanto, o projeto voltado para o mercado ganhou essa luta, com a aprovação da nova LDB, em 1996. Forças voltadas ao outro projeto continuaram com certa influência, na esfera pública e, portanto, na esfera política. Habermas (HABERMAS, 1992, 2003, 1997) aponta para a esfera pública democrática como o lugar privilegiado para gerar um poder comunicativo com força suficiente para influenciar o núcleo político de uma sociedade. A despeito da ascensão das forças de mercado, no Brasil, nas últimas décadas, o fato é que os currículos de formação para a docência ainda possuem elementos voltados à formação humana e cultural e tal situação mostra que a esfera pública ainda funciona, embora sob constantes ataques.

Relativamente aos fundamentos da educação, aparecem, nos currículos, as seguintes disciplinas obrigatórias: Filosofia da Educação; Psicologia do Educação; Sociologia da Educação; Antropologia da Educação; História da Educação; História da Educação Brasileira; e Introdução ao Pensamento Científico em Educação. Embora essas disciplinas tenham como objetivo uma formação mais geral do aluno, orientada ao desenvolvimento dos processos de aprendizagem voltados à reprodução e racionalização do mundo da vida, não sempre estão vistas com bons olhos pelos professores dos cursos. Segundo as entrevistadas, tais disciplinas são trabalhadas de forma geral e, quase sempre, desvinculadas da prática docente. Conforme as palavras da entrevistada EA,

\footnotetext{
${ }^{6}$ Para Habermas (2012), a integração social não se dá via mercado, mas por meio de relações interpessoais que dão continuidade à identidade social.
} 
fundamentos da educação, coitado deste aluno, às vezes ele nem pensa necessariamente, dependendo do professor que ele pegue, às vezes, ele nem tá pensando na escola, educação pública ou na educação no sentido mais amplo ou... não, esse é um problema que a gente vive.

Apesar da presença de tais disciplinas no currículo obrigatório, há descontentamentos em relação a sua articulação com a prática escolar. Conforme afirma a entrevistada EB, "isto tem sido um problema enorme, disciplinas são dadas por pessoas que não tem muita relação com a educação básica". Em contraponto, isso reflete o que Flickinger (2014, p. 45) denomina de "sobrevalorização da prática pedagógica", a qual termina "na juridificação dos conflitos ao invés de sua mediação pelo diálogo". Em realidade, a presença de tais disciplinas nos currículos, anuncia, de certa maneira, uma resistência em relação à tendência mais mecanizada da formação docente voltada à perspectiva do desempenho e da eficiência. Por meio dos fundamentos teóricos da educação, os cursos, apesar de demonstrarem dificuldade em dialogar com a escola básica, asseguram espaço para o desenvolvimento de condutas refletidas e críticas, necessárias à formação comprometida com a dimensão simbólica do mundo social, cultural e das identidades individuais.

Em relação à autonomia das faculdades para organizarem os cursos, os coordenadores ressaltaram a flexibilidade permitida pelas próprias diretrizes curriculares. Como ressalva a entrevistada $\mathrm{EB}$,

a gente tem visto no grupo que está olhando para essas resoluções e pensando o currículo como a possibilidade de existência de uma autonomia para seguir determinadas possibilidades dentro deste perfil que nós definimos.

Arriscamos dizer que essa flexibilidade seja resultado das lutas sociais, políticas e educacionais mencionadas anteriormente neste artigo. Entretanto, segundo a entrevistada EB, as discussões, no NDE, são longas e bastante tensas, não sendo fácil chegar a acordos, em vista do conflito de interesses presentes nas discussões. As diferenças formativas discrepantes dos docentes, o interesse pela garantia do espaço temático para pesquisa e extensão e as linhas ideológicas contrárias, nem sempre incluídas à vontade de entendimento, têm prejudicado as decisões acerca da formação. Mas essa situação é de ser esperada numa sociedade dividida. Por que esperar que os professores universitários não refletiriam as divergências ideológicas, sociais e políticas da sociedade como um todo? É provável que a ausência de consenso, em torno da identidade do curso, somada à falta de precisão das DCNP, tem potencializado os desacordos. No entanto, a existência de um debate, mesmo não chegando a um consenso, poderia ser visto como um aspecto positivo, pois revela uma abertura para chegar a um entendimento mútuo ${ }^{7}$.

Os cursos têm procurado atender às demandas profissionais colocadas pelas DCNP, por meio de adaptações curriculares para satisfazer a exigência ampliada de formação, sem deixar de responder às necessidades contextuais, às condições do corpo docente e ao sentido da formação universitária. Contudo, apesar dos esforços internos, existem obstáculos que ultrapassam as suas condições. Ficou claro que as diretrizes curriculares não correspondem a sua viabilidade da implementação, basta observar os currículos dos cursos os quais não contemplam de forma equilibrada as modalidades sugeridas. Por isso, o propósito de formação de um profissional (docência ampliada), para a atuação, em diferentes espaços, num único curso, mostrou-se uma tarefa difícil de ser alcançada. Conforme a fala da entrevistada EB:

o nosso curso está voltado pra formar esse pedagogo, mas principalmente esse pedagogo que vai atuar como docente. Tem um lado também de um pedagogo que vai ser pesquisador, que vai atuar em outras áreas, mas tem este lado de atuar na escola pública. (...) E até pensando no currículo novo que a gente está trabalhando, a primeira coisa que a gente teve que fazer foi justamente definir o perfil. E foi definido o perfil do pedagogo que nós queremos formar,

\footnotetext{
${ }^{7}$ Habermas faz uma distinção importante entre compreender (Verstehen), chegar a compreender algo de uma maneira parecida (Verständnis), chegar a um entendimento mútuo (Verständigung) e chegar a um acordo sobre algo (Einverständnis). Todos esses termos foram traduzidos para o português como entender ou compreender (BANNELL, 2013). Nesse sentido, em tal perspectiva, não é necessário chegar a um acordo sobretudo, na esfera pública ou na ação comunicativa em geral. Educação em Revista|Belo Horizonte|v.36|e231370|2020
} 
aquele que vai atuar prioritariamente na educação básica pública. É isto que a gente está focando, vamos ter aí um esforço em dar mais prioridade ainda.

Podemos perceber que há, nos cursos, uma enorme preocupação e dedicação em relação à profissionalização do pedagogo, tendo em vista a reflexão sobre seu perfil. Entretanto, diante das exigências de diferentes modalidades formativas, adicionadas à falta de clareza das diretrizes, dos obstáculos da especialização dos professores, da dificuldade de comunicação entre as diferentes orientações ideológicas presentes no corpo docente e da desvalorização da carreira, que influencia diretamente na motivação e no perfil do estudante, os problemas têm se acumulado progressivamente. No entanto, cabe perguntar se esses problemas não refletem um contexto no qual o debate, na esfera pública, não foi totalmente capturado por um lado, deixando pelo menos uma brecha para um "argumento surpreendente" dentro de um Discurso Prático - uma das formas reflexivas da ação comunicativa - orientado ao entendimento mútuo.

Todavia, conforme a análise curricular das disciplinas de Fundamentos da Educação e do espaço para as atividades de pesquisas e de extensão ${ }^{8}$ existentes nos cursos, somada ao viés crítico e social das propostas pedagógicas identificado, nos documentos e nas entrevistas, parece ainda permitir o que previa Habermas (2012), ao sugerir que a racionalidade devesse preocupar-se com a reprodução e crítica dos elementos do mundo da vida, necessários à integração social, à solidariedade e ao desenvolvimento do sujeito capaz de comunicação e ação para além dos interesses apenas mercadológicos.

Embora já tenham sido publicadas novas diretrizes curriculares nacionais para a formação inicial de professores para a educação básica (2019), até o presente momento, os cursos permanecem com a mesma estrutura e organização, tendo em vista o prazo de dois anos, para a adequação ser realizada. Ao que parece, tais diretrizes, as quais não foram objetos de nosso estudo, dão uma guinada nas fragilidades em torno da formação das competências e habilidades para a atuação na escola básica, focam na preparação profissional para a docência, nos anos primários e na educação infantil, em detrimento de uma formação mais humanística, que aproximaria o curso da perspectiva em voga na Alemanha. Aliás, se isso for a consequência dessa nova reforma, fortaleceria a hegemonia do projeto mercadológico, na sociedade brasileira, vista nos últimos anos, e seu reflexo nas políticas públicas para a educação.

\section{Formação docente para os anos primários em universidades alemãs}

Toda formação docente na Alemanha é de responsabilidade do estado, tendo cada um dos 16 estados uma legislação própria. ${ }^{9}$ As legislações dos estados seguem as normas educacionais definidas pela Conferência Permanente de Ministros da Educação e Cultura (Kultusministerkonferenz - $\mathrm{KMK}^{10}$ ), pensadas a partir das orientações do Processo de Bolonha que foram acertadas no âmbito europeu. Neste artigo, trataremos da legislação sobre a formação docente para os anos primários do Estado da Renânia do Norte-Vestfália (Nordrbein-Westfalen - NRW, LABG e LZV, 2016) e de duas de suas universidades. Considerando os intercâmbios em curso, o que facilitaria fazer pesquisa no exterior, selecionamos duas universidades que já realizavam trabalhos com a nossa linha de pesquisa e que se colocam como representativas do que está acontecendo na Alemanha no momento atual ${ }^{11}$.

No Estado da NRW, todos os cursos de formação de docentes são universitários e se orientam pela Lei de Diretrizes da Formação Docente (Lehrerausbildungsgesetz - LABG) que entrou em vigor no dia 26 de maio de 2009, tendo a sua última revisão em 14 de junho de 2016, bem como pelo

\footnotetext{
${ }^{8}$ O Plano Nacional de Educação (PNE) 2014 -2024 indica como estratégia da meta 12: "que as instituições deverão assegurar, no mínimo, dez por cento do total de créditos curriculares exigidos para a graduação em programas e projetos de extensão universitária, orientando sua ação, prioritariamente, para áreas de grande pertinência social” (BRASIL, 2014).

${ }^{9}$ Mais detalhes sobre a organização do sistema educacional alemão, cf. Hilligus (2015) e Döbert (2015).

${ }^{10}$ Para mais informações, cf. https://www.kmk.org/kmk/information-in-english.html. Acesso em: 17 abr. 2017.

${ }^{11} \mathrm{Um}$ fator de comparação é que essas reformas foram apresentadas na mesma época em ambos dos países, refletindo claramente os imperativos sociais, políticos e econômicos em cada país.
} 
Decreto de Acesso ao Exercício da Docência (Lehramtszugangsverordnung - LZV), que, no Estado da NRW, foi atualizado pela última vez em 25 de abril de 2016. De acordo com a LABG e o LZV, os Estados e as universidades devem se comprometer com a formação dos docentes, levando em consideração os desafios educacionais e as necessidades das escolas nas suas diferentes especificidades. $\mathrm{Na} L A B G$, os objetivos da formação são assim definidos:

(1) Objetivo da formação é a capacitação para o exercício da docência em escolas públicas de forma autônoma. Os requisitos exigidos na formação do corpo docente para o exercício da profissão, são regidos pelo $\int 102$ da Lei Escolar do NRW ${ }^{12}$.

(2) A formação é dividida em estudo e serviço preparatório. A formação inicial e continuada, incluindo o ingresso na profissão, se orienta pelo desenvolvimento de competências profissionais básicas para o ensino e a educabilidade (Erz̧iebung), avaliação, diagnóstico, orientação, cooperação e desenvolvimento escolar, bem como para as exigências científicas e artísticas das disciplinas. Nisso compreende-se a capacidade de lidar profissionalmente com a diversidade, sobretudo, com vistas a um sistema escolar inclusivo, bem como a capacidade de cooperação particularmente com os pares, com os pais, com outros grupos profissionais e outras instituições. A formação deve desenvolver a capacidade e fortalecer a disposição para o reconhecimento, incentivo e desenvolvimento das potencialidades e habilidades individuais de todos os alunos e alunas.

(3) O serviço escolar e a preparação para o serviço pressupõe o domínio da língua alemã, que possibilite o seu uso em sala de aula e no desempenho de todas as atividades de um docente. (NRW, 2016, art. 1º, s 2).

Segundo a LABG (2009/2016), os cursos de formação devem preparar os docentes para exercer a profissão de forma autônoma. O estudo nas duas fases (bacharelado - 3 anos e mestrado - 2 anos) promove o desenvolvimento de competências profissionais básicas para o exercício no magistério atendendo às exigências apontadas na LABG e no LZV, conforme explicaremos mais adiante.

Quanto aos cursos de formação de docentes para os anos primários (Lebramt an Grundschulen), além do componente curricular obrigatório denominado Ciências da Formação (Bildungswissenschaften), a LABG (NRW, 2016, art. $3^{\circ}$, \ 11; 6.1) definiu como parte obrigatória os estudos relacionados às áreas de "formação básica em linguística e formação básica em matemática, bem como uma outra área de aprendizagem ou disciplina escolar, acrescidos das didáticas específicas". A carga horária dos cursos e créditos a serem cursados em cada área de estudo é regulamentada pelo LZV, apresentando a seguinte distribuição (NRW, 2016, \4):

- Área I - Formação básica em letras / língua materna (55 LP13);

- Área II - Formação básica em matemática (55 LP);

- Área III - Formação em outra área do conhecimento ou outra disciplina, acrescido das didáticas específicas (55 LP);

- Aprofundamento nas áreas I, II ou III ou em uma disciplina escolar (12 LP);

- Ciências da formação / Bildungswissenschaften ${ }^{14}$ (64 LP);

- Alemão para alunos e alunas com histórico familiar de migração (6 LP);

- Semestre prático (25 LP);

- Trabalho de conclusão de curso de bacharelado e mestrado (28 LP).

A carga horária total dos cursos é bastante extensa, mesclando uma formação por meio de estágios, cursos de leitura (Vorlesung), aulas expositivas, seminários, aulas on-line e estudos individuais, o que atende à perspectiva de desenvolvimento das normas educacionais (cf. KMK, 2004). São cerca de

\footnotetext{
12 Redação do $\int 102$ da Lei Escolar da NRW, disponível em: http://www.lexsoft.de/cgibin/lexsoft/justizportal_nrw.cgi?xid=492252,103. Acesso em: 17 abr. 2017.

${ }^{13} \mathrm{LP}=$ Leistungspunkte (equivalente a créditos).

14 A área de aprendizagem "ciências da formação" é obrigatória para todos os tipos de magistérios, mas é trabalhada com mais ênfase no magistério para os anos primários. 
9.000 horas previstas entre mestrado e bacharelado, mais 18 meses de residência escolar (Referendariat) depois da conclusão do mestrado e, por último, a realização do exame de Estado (Staatsprüfung) que habilita o ingresso na carreira. A distribuição de créditos nas diferentes áreas de aprendizagem indica a preocupação tanto com a formação em conteúdos específicos a serem aprendidos, com as didáticas do ensino dos conteúdos, como com a experiência prática e às Ciências da Formação.

$\mathrm{Na}$ área de estudo III, de livre escolha dos estudantes, são oferecidas as seguintes possibilidades de acordo com o $\int 4$ da LZV (NRW,2016): a) estudo de ciências naturais e sociais (Sachunterricht) ou educação estética (Ästhetische Eræiebung); b) estudo de uma disciplina específica, entre: inglês, ensino da religião evangélica/luterana, ensino da religião islâmica, ensino da religião católica, artes, música ou esporte; e c) aprofundamento no ensino do alemão para alunos e alunas com histórico familiar de migração com possibilidade de integralização de créditos por meio do estudo de uma língua de origem da população com antecedentes migratórios. Os temas e conteúdos a serem trabalhados nas áreas de estudo I, II e III nos respectivos cursos universitários não são detalhados na LZV. Já em relação ao componente Ciências da Formação, que compreende a maior carga horária dos cursos (64 LP ou cerca de $22 \%$ da formação), a LABG (NRW, 2016, \11, 6.1) define que os estudos concentramse "na aprendizagem precoce, incluindo aspectos centrais da pedagogia dos anos elementares e da pedagogia do desenvolvimento". A LZV, por sua vez, detalha em seu $\int 2$ os conteúdos a serem contemplados nesse componente, a saber: Ciências da Formação, incluindo a pedagogia dos anos primários; elementos da práxis; conceitos da formação e educação pré-escolar; diagnóstico e incentivo/estímulo (como parte integrante das didáticas específicas); questões/temas relacionados à inclusão; produções relacionadas a questões específicas da inclusão de alunos e alunas com necessidade de atendimento pedagógico especial.

De uma forma geral, observamos que a formação para a docência nas escolas primárias do Estado NRW, tal como determinado na LABG e no LZV, se orienta pelo princípio do paradigma das competências acordado em 2004 no âmbito do Parlamento e do Conselho da União Europeia, apresentando uma forte preocupação com a profissionalização técnica do docente, a aproximação da prática pedagógica, a inserção social e inclusão dos alunos com histórico familiar de migração. No contexto da Europa e da Alemanha dos últimas décadas, podemos ver as consequências do Projeto de Bolonha como resposta ao crise de competitividade e produtividade da economia europeia no mundo e a decisão do Parlamento e do Conselho Europeia de concentrar a economia na produção e distribuição de conhecimento (ROBERTSON, 2008, 2009a, 2009b, 2010). Como já mencionado anteriormente, houve um esforço na década de 70 de privilegiar uma formação para o mercado para substituir a formação tradicional alemã (Bildung) orientada a integração do indivíduo ao mundo da vida. Os imperativos dos subsistemas administrativo-político e e econômico na Alemanha resultou numa reforma do sistema educacional, das escolas até às universidades, que reduziu bastante a formação para o mundo da vida e ampliou o espaço para a formação profissional. ${ }^{15}$ Não há evidências que essa tendência terminou ou está sendo revertida. Pelo contrário, a evidência aponta na direção do fortalecimento de um sistema educacional orientado à formação de mão de obra para o mercado, inclusive a inclusão dos imigrantes nesse mercado, uma questão de central importância naquele país. (HAASLER, 2020)

\section{Organização atual dos cursos}

Podemos dizer que existem poucas diferenças na estrutura curricular dos cursos de formação para a docência nos anos primários nas duas universidades investigadas, que seguem as diretrizes elaboradas acima. $\mathrm{Na}$ instituição escolar, o docente da escola primária atua sempre com outros colegas, sendo cada docente responsável pelo ensino da matemática e do alemão além do ensino da disciplina em que se especializou. As disciplinas e demais atividades das áreas de estudo obrigatórias,

\footnotetext{
${ }^{15}$ Exemplos disso são o sistema de educação e treinamento vocacional, nas fábricas alemãs, vinculados às escolas secundárias, para a formação de mão de obra para a indústria (HAASLER, 2020 ), além das modificações nos cursos universitários das quais Habermas reclamou e chamou atenção em 1979 (HABERMAS, 1993). 
bem como da área de livre escolha, são cursadas nos respectivos departamentos ou institutos, de forma que os futuros docentes dos anos primários também realizam atividades com estudantes das licenciaturas para as escolas de nível secundário.

Os Institutos de Ciências da Educação, além da oferta de outros cursos de bacharelado e de mestrado, são responsáveis, em conjunto com os Institutos de Psicologia, apenas pela oferta do componente Ciências da Formação e pela disciplina "alemão como segunda língua" para alunos e alunas com histórico familiar de migração, o que corresponde a cerca de $22 \%$ das atividades previstas na estrutura curricular do curso voltadas para a docência nas escolas primárias.

Com a equiparação dos cursos de formação para a docência nos anos primários a formação de docentes para os níveis subsequentes, no que diz respeito ao tempo de estudo e à titulação, exigindose a realização do bacharelado e do mestrado, essa formação passou a ser mais valorizada. ${ }^{16}$ No contexto alemão, mesmo com uma diferenciação entre salários, a carreira de professor ainda é atraente e os alunos dos cursos ainda contam com ingressos da forte classe média no país, que tem um nível de igualdade bem melhor que o Brasil. Além disso, o Processo de Bolonha tinha como objetivo principal facilitar a migração de docentes entre os país da União Europeia, portanto resolvendo o problema de falta de professores em alguns países. Por esse motivo, foi proposta uma unificação dos cursos de formação de professor em todos os países, proposta essa que teve como objetivo suprir a falta de mão de obra qualificada nos respectivos países, para enfrentar a competitividade numa economia globalizada pela mobilidade internacional de conhecimento especializado.

Segundo a entrevistada EF1, com a LABG 2009, lei para a formação de professores de 2009, o curso universitário para professores da escola primária passou a ter o mesmo valor que todos os outros. Contudo, a segmentação entre bacharelado e mestrado não tem sido interessante para a formação para o magistério, tendo em vista a obrigatoriedade da realização dos dois cursos. Para os entrevistados, tal padronização (bacharelado e mestrado) não incentivou a mobilidade internacional objetivada pelo processo de Bolonha, pois, diante das diferentes exigências em relação à formação do docente em cada país, os currículos continuaram diferentes. Segundo as palavras do entrevistado EM1,

tentamos unificar os cursos, mas não conseguimos, vendo as coisas agora dependia dos fatores mais diversos, o pessoal docente a disposição da universidade etc. (...) então a grande ideia da mobilidade, exato, não funcionou (...), esse é um primeiro ponto. Esse é o primeiro ponto que não funcionou, nenhuma mobilidade, até reduziu a mobilidade.

Pela dificuldade de unificação dos currículos dos cursos, a separação entre bacharelado e mestrado também tem ocasionado problemas burocráticos no momento da transição de um curso para o outro. Segundo o entrevistado BM1,

o problema deste formato bacharelado mestrado é a passagem de um pro outro (...), chega ao ponto que qualquer coisa mínima que não funciona se criam grandes problemas (...) os estudantes perdem um mês de bolsa, porque concluíram o curso, mas a inscrição no outro ainda não funcionou. Nós temos uma quantidade infinita de pedidos para mudar datas de provas de modo que os estudantes possam passar sem perdas de um curso para o outro.

Apesar das críticas em torno dessa padronização, os entrevistados apontam como positiva a obrigatoriedade do foco do bacharelado na docência, pois antes se formava o bacharel polivalente que muitas vezes não sabia o que iria fazer quando concluísse o curso. Segundo o entrevistado EM1, só depois do bacharelado era preciso tomar uma decisão, "agora se estuda desde o começo para se tornar docente, no bacharelado e no mestrado, e isso é correto". Tal mudança teria fortalecido a formação do docente que, agora, desde o início, já tem o foco na escola. Vale destacar aqui que a possibilidade de ter um curso tão longo, dividido em duas fases e componentes diversificados, inclusive residência escolar, reflete a situação econômica da Alemanha, país mais rico da Europa. O governo tem como investir

\footnotetext{
${ }^{16}$ Apesar dessa valorização, os docentes dos anos primários ainda recebem um salário menor em relação aos docentes dos demais níveis de ensino.
} 
pesadamente na educação, em todos os níveis, que está refletido na estrutura e duração dos cursos de formação examinados nessa pesquisa. No entanto, esse investimento não produziu resultados somente benéficos para os alunos universitários. A preocupação de Habermas, na década de 70 , sobre o lugar das humanidades e os processos de aprendizagem voltados ao mundo da vida não poderia ser considerada sem mais sentido. Pelo contrário, poderia dizer que a unificação da União Europeia, no sentido econômico, mas também cultural e político, tem produzido uma espécie de consenso em volta de neoliberalismo econômico e uma padronização cultural que está eliminando, ou pelo menos reduzido bastante, a pluralidade cultural e de mundos da vida que caracterizou a Europa anteriormente. A Alemanha ganhou competitividade dentro da Europa e no mundo como um todo, mas esse ganho econômico não veio necessariamente com um ganho em termos da racionalização do mundo da vida e ampliação da esfera pública. ${ }^{17}$

As Ciências da Formação articulam, principalmente, saberes das seguintes áreas: Ciências da Educação, Psicologia Escolar e do Desenvolvimento Humano, conhecimentos sociológicos sobre a escola e seus sujeitos e, às vezes, conhecimentos filosóficos articulados a questões relevantes para os futuros docentes. Conhecimentos sobre processos de socialização e escolarização de crianças com histórico familiar de migração também constituem um eixo central em alguns módulos ministrados na parte das Ciências da Formação. O objetivo é oferecer ao estudante um saber profissional fundado, orientado ao campo da ação pedagógica, que permita a ele identificar questões e problemas pedagógicos relacionados à prática escolar. Considerando a preocupação com o desempenho dos docentes na gestão em sala de aula, são enfatizadas as Ciências da Educação, com foco nas discussões pedagógicas aplicáveis na prática, e a Psicologia Escolar, com foco nos diagnósticos das habilidades e competências e aprendizagem na infância. Entretanto, apesar da significativa carga horária (22\%), o componente Ciências da Formação não parece abordar as discussões socioculturais de reprodução e crítica das estruturas simbólicas da cultura (conhecimento), da sociedade (ordem legítima) e da personalidade (identidade individual), conforme sugerido por Habermas (1993) para a formação universitária, o que demonstra a preocupação com uma formação mais voltada para o mercado profissional.

Segundo os entrevistados, o conceito de ciência da formação, termo para denominar uma parte da formação docente, ainda é bastante problemático, porque contempla áreas diferentes como a psicologia e as ciências da educação, que possuem, muitas vezes, posições contrárias em relação à formação docente. Segundo os entrevistados:

temos posições muito diferentes... em parte posições completamente contrárias entre si. (EF2)

Temos que ficar de olho para que a psicologia não fique dominante, pois é automático... quando se repartem as componentes curriculares cada disciplina se acha a mais importante, mas nós, como se sabe, somos os mais importantes, mas além disso... além disso há sempre tensões, ou pequenas tensões...e de que é a vez, quem está representado. (EM1)

Trata-se de uma área de aprendizagem que tem sido discutida interna e externamente à universidade com muitas tensões devido às diferentes orientações científicas envolvidas. Além das diferenças entre as áreas científicas, a área precisa lidar com sua desvalorização pelos didáticos das matérias específicas da formação. No entanto, a existência de uma discussão sobre essa questão já aponta para algum espaço para o discurso prático orientado às questões morais, éticas, jurídicas e políticas, evidencia que as esferas de discussão e argumentação dentro das universidades ainda persistem, embora reduzidas, refletindo a existência de uma esfera pública alemã onde tais questões e reinvindicações podem ser expressas e articuladas.

Mas, em geral, a formação segue o padrão de competências acordado no âmbito federal (KMK/2004) e adaptado no nível estadual. Segundo a entrevistada EF1, "nós respeitamos, numa visão geral, os padrões para a formação de professores, as competências". O estado estabelece as áreas de

\footnotetext{
${ }^{17}$ Embora Habermas seja um apoiador forte à União Europeia, politica e culturalmente, ele está sempre criticando os aspectos negativos dessa União (HABERMAS, 2001, 2004). 
aprendizagem, as competências a serem alcançadas e o número de créditos, mas os cursos podem se desenvolver a partir de suas características contextuais e de seus focos de pesquisa. Os professores podem debater as diretrizes da formação docente num nível político, mas não podem descumprir a legislação ${ }^{18}$.

Assim, mesmo considerando que a divisão entre bacharelado e mestrado não seja a mais adequada para os cursos de formação de docentes, as universidades têm buscado se adaptar às novas regras e organizar os cursos da melhor forma possível. Trata-se de uma orientação legal que atua na universidade sem grandes resistências, tendo em vista a aposta no modelo de profissionalização por competências ${ }^{19}$. Para os entrevistados:

o estado é responsável que o pessoal da escola seja qualificado e, se tem essa responsabilidade, deve poder governar a sua formação (...) e essa também uma obrigação da universidade: gente, formem bem os nossos professores (...) os alunos não podem fugir dos professores. (EM1, grifo nosso)

Liberdade de pesquisa e ensino, essa é a questão aqui (...) esta liberdade aqui é limitada: há regulamentos $(. .$.$) os setores, que eles devem estudar...os créditos, então há indicações$ também sobre os conteúdos que devem ser ministrados. (BM2)

A tendência atual das universidades estudadas, pelo menos no que se refere aos cursos de formação para os anos primários, é quase exclusivamente a formação das competências para o exercício prático na escola pública. Como afirma o entrevistado EM1,

no nível federal, existem padrões para a parte de ciência da formação, padrões de competências, os estados devem adaptar esses padrões ao seu contexto, e isso aconteceu $(. .$. os padrões são formulados sempre de forma muito geral (...) os campos de competência são dar aulas, educar, avaliar, aconselhar, inovar e formação continua (...) esses campos existem há décadas... dar aulas, educar, avaliar, aconselhar, inovar e se formar, um professor tem que saber fazer tudo isso (risadas) e isso é concretizado nos planos dos cursos, nos manuais sobre os módulos, nos seminários... e assim se espera, por assim dizer, que surgiam estas competências. $^{20}$

A partir dos acertos realizados no âmbito da KMK, o Ministério da Educação estabeleceu que é tarefa da universidade formar o docente com competências práticas, e essa instituição está se esforçando ao máximo para atender à regulamentação. Com esse compromisso, a universidade parece deixar a formação cultural mais ampliada (no sentido da antiga Bildung) a critério dos estudantes, já que esses não estão impedidos de frequentar outras disciplinas e atividades que não fazem parte da estrutura curricular obrigatória do seu próprio curso.

Contudo, diante da grande quantidade de créditos obrigatórios, das diversas habilidades exigidas e da enorme quantidade de estudantes nos cursos, obviamente há pouco tempo para atividades voltadas para outros interesses dos universitários. Além disso, a universidade está tendo que se adaptar ao novo perfil de estudante, muitos oriundos de famílias cujos pais não possuem curso superior e outros com histórico familiar de migração. Por isso, esses estudantes estão mais focados na profissionalização técnica, se empenhando na formação específica e nos aspectos da universidade que irão trazer benefícios no que se refere à empregabilidade ${ }^{21}$. Segundo a entrevistada EF1,

\footnotetext{
${ }^{18}$ Essa possibilidade remete à exigência de Kant (2011) que profissionais deveriam usar publicamente sua razão enquanto obedecendo as restrições do uso privado da razão dentro das instituições do Estado. O conceito de esfera pública é extensão dessa ideia de um espaço para o uso público da razão sugerido pelo autor como necessário para o esclarecimento.

${ }^{19}$ Essa falta de resistência mostra um "consenso" (falso ou verdadeiro?) na sociedade alemã, sobre os objetivos da educação, algo ainda ausente no Brasil.

${ }^{20}$ É possível detectar nessas falas certo ceticismo em relação aos objetivos e ao conteúdo dos cursos, especialmente o comentário que a liberdade dos cursos "é a questão aqui".

${ }^{21}$ Essa mudança no perfil do alunado na Alemanha reflete mudanças sociais e econômicas no país, especialmente, o crescimento da imigração e a necessidade de mão de obra para a produção industrial do país. No entanto, ainda é verdade dizer que a profissão de docente á mais atraente no Alemanha do que no Brasil e o salário bem melhor. 
temos muitas pessoas que são as primeiras a estudar nas suas famílias e, depois, temos muitos estudantes com uma história familiar de imigração (independentemente do conceito que queremos usar para definir esse fenômeno), (...) para nós esse é um tema não apenas no ensino mas também no desenvolvimento da própria universidade (...) o estudo se parece mais com a escola, eles estão cheios de tarefa (...) Os estudantes são heterogêneos, temos muitos estudantes com um histórico de migração, que vem de famílias de não acadêmicos (...) É claro, muitos focam na profissão e no estado social, com certeza... não quero dizer que isso tem algo a ver com a diminuição do engajamento (...) mas é o caso de muitos.

Diante de um currículo pouco flexível, com estudos focados no desempenho da docência na escola e de uma grande quantidade de créditos obrigatórios, há pouco tempo para aprendizagem voltada para às demandas do mundo da vida, que permitiria não apenas a interação crítica com as necessidades da economia e da administração, mas também o atendimento às funções de reprodução criticamente motivado da cultura e da integração social. Gruschka (2015, p. 279), analisando a universidade alemã, diz que

os criadores da nova educação estão cheios de ingenuidade, eles são extremamente operativos, porque não há nenhum escrúpulo educacional que possa retardá-los. Conceitos como o de educação clássica (Bildung), o qual liga as pessoas com a continuidade de sua história, as preparando para as tarefas do futuro, são considerados desatualizados, sem interesse, inúteis, os quais nem mesmo agregam valor de distinção. Atrás disso há um interesse comercial.

Apesar das críticas presentes no que se refere ao paradigma das competências, as universidades procuram formar docentes de acordo com as normas educacionais acordadas pela KMK e adaptadas pelos respectivos Estados. Entretanto, a forma de ensino e a de avaliação por meio de exames ainda não corresponde à perspectiva do paradigma que propõe ir além do ensino e da verificação dos conteúdos aprendidos. Segundo o entrevistado EM1,

a orientação sobre competências é um tema muito debatido (...) tradicionalmente se ensinavam conteúdos... vocês têm que saber isso, isso e isso e nós verificávamos se os estudantes sabiam (...) hoje em dia temos que verificar competências, mas verificar competências é muito difícil então continuamos a verificar conteúdos (...) essa é uma carência que temos (...) sim, podemos dizer, novas formas de exame, de provas acadêmicas, não as temos, e se somos sinceros, nós aplicamos as provas desde anos, desde décadas sempre segundo o mesmo esquema, no mesmo modo (...) verificamos conteúdos.

As habilidades docentes acabam sendo levadas em consideração somente durante a residência pelos responsáveis por essa etapa de avaliação, ou seja, pelo docente que acompanha o residente e pelos supervisores dos Ministérios de Educação de cada Estado designados para essa função. Gruschka (2015, p. 276) faz a crítica dizendo que "o que deve acontecer didaticamente não é mais decidido por professores com a sua tarefa educativa, mas sim, e acima de tudo, pelos vendedores e gerentes de produção da retórica das competências, orientados externamente na auto-eficiência". Os gestores das universidades "já não têm a ciência como objetivo, mas sim a tem como um meio para o lucro dos negócios” (GRUSCHKA, 2015, p. 276).

Tal experiência de formação parece acentuar, cada vez mais, a desacoplagem do mundo social do sistêmico. Pela compreensão habermasiana (2012), uma formação focada no sistêmico se guia pela lógica instrumental que é insuficiente no tratamento dos problemas sociais, isso porque os desvios ou as patologias desse âmbito nem sempre são provocados pelas objetivações da sociedade, mas pelas comunicações sistematicamente distorcidas. A ideia de que a sociedade atual se constitui como totalidade organizada apenas pelo trabalho não é mais razoável se pensarmos no compromisso da formação diante das descentralizações sociais cada vez mais exigentes e das necessidades comuns decorrentes do mundo da vida. No entanto, no país mais rico da Europa, com sua tradição de formação humanística voltada ao mundo da vida, não é esse o foco da formação do professor, à luz do 
estudo feito nessa pesquisa. Pelo contrário, a ideia tradicional da universidade, elogiado por Humboldt e resgatado por Habermas (1993) já está em vias de extinção.

\section{DIFERENÇA DOS MODELOS DE FORMAÇÃO DOCENTE DAS EXPERIÊNCIAS EM UNIVERSIDADES BRASILEIRAS E ALEMÃS}

O artigo interroga se a formação de professores para os anos primários ocorre a partir dos requisitos da profissão ou de interesses do "mundo da vida", tendo como suporte teórico o pensamento de Habermas. Diante dessas questões, o trabalho aponta possibilidades de contribuição de estudos na perspectiva proposta e de ampliação do diálogo teórico para o campo da formação.

Em função das análises realizadas, podemos dizer que existem esforços nos cursos investigados em ambas as realidades, mesmo que às vezes isolados, para garantir a unidade formativa no que se refere à profissionalização técnica e ao atendimento das necessidades do mundo da vida. Entretanto, os cursos parecem não estar conseguindo fazer de forma equilibrada, tendo em vista o enfoque formativo e as políticas educacionais de cada um dos países. Diferente do Brasil, as diretrizes na Alemanha são mais bem definidas no que se refere à formação profissional. Analisamos a estrutura curricular considerando as disciplinas presentes nas matrizes dos cursos pesquisados, tendo em vista a crítica de uma abordagem disciplinar que dissocia teoria e prática. Na Alemanha, como vimos, os cursos são específicos para a formação do docente de anos primários e seguem o paradigma das competências orientados pelo Processo de Bolonha, focando, portanto, na formação mais especializada. No Brasil, a pedagogia precisa atender às diretrizes para uma formação mais generalista, não conseguindo focar na formação do professor para os anos primários de forma suficiente, embora ofereçam mais espaços de diálogo com o mundo da vida necessários à formação humana. Apesar de a compreensão de docência ampliada estar bem fundamentada nas discussões que permitiram a elaboração das DNCP, muitas dificuldades se manifestaram na sua implementação nas universidades investigadas, principalmente, no que se refere a falta de entendimento sobre o compromisso formativo do curso.

A compreensão é de que, na tentativa de garantir a manutenção do curso de pedagogia, diante dos encaminhamentos históricos para a sua extinção, e a defesa de que a formação do professor para esta etapa do ensino deveria acontecer em nível superior, foi estabelecido o compromisso com a educação infantil e com os anos primários, o que, a princípio, parece ter sido a solução. Como se trata de um curso de pedagogia, com pouco espaço para as disciplinas específicas das matérias de ensino, foram assegurados os fundamentos da educação que, entretanto, como ficou constatado nas entrevistas, não têm conseguido se articular com a prática pedagógica. No entanto, os debates e embates sobre a formação de professores no Brasil, que, por sua vez, refletem as lutas sociais e políticas entre dois projetos para o país (CUNHA, 1989, 1995, 2007), elaborados desde a redemocratização, podem ser vistos como evidência de uma falta de consenso sobre o destino do país. Essa falta de consenso não deveria ser interpretada, à luz da teoria da ação comunicativa de Habermas, como negativo, mas como um esforço constante de articular pontos de vista, via diálogo, para tentar resolver os graves problemas sociais, econômicos e políticas que o país enfrenta. ${ }^{22}$

Mesmo para uma carga horária de somente 3.200 h, e uma demanda para a formação em diferentes modalidades de atuação, os cursos conseguem ofertar um ambiente para que haja discussões sobre processos de socialização, debates críticos sobre fatos atuais, continuidade e reconstrução dos saberes culturais, tomada de posição política e formação de solidariedade grupal, embora não haja um direcionamento preciso para isso nos projetos político-pedagógicos (PPP). Conforme os currículos analisados, os cursos preveem lugar para a discussão das estruturas simbólicas da cultura que permitem a transmissão e a renovação do saber cultural, a coordenação das ações que possibilitam a integração social, a solidariedade e a socialização que permite a formação de identidades pessoais, necessidades estas já manifestas por Habermas $(1993 ; 2012)$, para que seja possível uma formação técnica articulada

\footnotetext{
22 Os acontecimentos nos últimos 5 anos apontam na direção de uma tentativa daqueles comprometidos com os interesses do mercado de reduzir se não fechar o espaço de diálogo, na esfera pública como dentro das instituições de ensino.

Educação em Revista|Belo Horizonte|v.36|e231370|2020
} 
com o mundo da vida na universidade.

Isso significa que, apesar de não conseguirem atender, de forma suficiente, às exigências profissionalizantes e técnicas das diretrizes (GATTI, 2010), existe nos currículos a preocupação, de forma não categórica, com uma formação que contemple os aspectos referentes à cultura, à sociedade e à personalidade, indicando uma abertura para uma formação mais integrada, como propõe a teoria comunicativa de Habermas, caso fosse possível articular melhor à profissionalização técnica.

Dessa forma, no Brasil, devido à crise de identidade dos cursos de pedagogia, a tentativa de atender a ampla reivindicação das entidades envolvidas e à preocupação com a empregabilidade do pedagogo, as diretrizes são mais flexíveis, oferecendo, portanto, mais autonomia que se evidencia na diferença de enfoque, de estrutura e de perspectivas de formação existentes nos cursos. Pelo fato de as diretrizes não definirem a identidade do pedagogo de forma explícita (LIBÂNEO, 2013; SAVIANI, 2012), de apresentarem diferentes campos de atuação sem definição de carga-horária e de oferecerem espaço para a adaptação da formação conforme as necessidades de cada contexto, os cursos possuem mais condições de autodeterminação de seu foco e organização. Apesar de os cursos em ambos os países serem avaliados externamente, existe no Brasil uma liberdade maior na escolha da perpectiva pedagógica, das prioridades dos cursos e da organização curricular, o que, devido às dificuldades de entendimento, nem sempre resulta em decisões bem-sucedidas na prática.

Não há dúvidas de que o modelo alemão de formação do docente para anos primários investigado, com carga horária de 9.000 horas (entre bacharelado e mestrado), referentes às matérias específicas de ensino e suas didáticas, às ciências da formação e às práticas de estágio para formação específica do docente que irá atuar nos anos primários, somado a 18 meses de residência escolar (Referendariat) depois da conclusão do mestrado e, por último, à realização do exame de Estado (Staatsprüfung), que habilita o ingresso na carreira, permite uma profissionalização mais voltadas ao atendimento das necessidades da escola pública e à demanda proveniente do mercado.

No entanto, teóricos críticos como Gruschka (2015) apontam que o recuo das Ciências da Educação em favor das Ciências da Formação (Bildungswissenschaften) ${ }^{23}$ levou os cursos de formação docente na Alemanha a decretar a falência do seu compromisso com a formação cultural mais ampla (Bildung), por sua equiparação com a psicometria e com a economia empresarial. No entanto, no que se refere aos saberes básicos para o ensino em sala de aula, podemos dizer que os docentes formados nesses cursos parecem estar tecnicamente mais preparados do que se observa nos cursos analisados do Brasil.

Em contrapartida, percebemos nas universidades alemãs investigadas um estreitamento do espaço para as discussões sociais mais críticas, voltadas para renovação da cultura, com poucas possibilidades dentro da estrutura curricular. Considerando o cerne no desenvolvimento de competências e na formação por módulos fechados, parece não sobrar muito tempo à ampliação dos horizontes de discussão no tocante às necessidades do mundo da vida, o que se soma à falta de interesse dos estudantes, que estão centrados na empregabilidade. Além disso, no próprio currículo, percebemos os módulos direcionados à atuação bem-sucedida na prática, convertendo, por exemplo, os módulos das Ciências da Formação em espaço de estudos mais aplicáveis à docência na escola. Segundo EM1,

ciências da formação realmente são melhores que 20, 40 anos atrás (...) isso vem do fato que nós agora focamos a atenção para que na docência sejam oferecidos conteúdos que sirvam aos professores, e não aos nossos hobbies científicos, por assim dizer (...) temos que ter um controle sobre isso, temos que nós engajar (...) e está funcionando (...) claro que os professores têm liberdade de ensino, mas eles devem organizar os seus programas, os tópicos dos cursos, e devem formular as coisas de modo que caibam nos módulos (...) alguns professores fazem isso sem se queixar, outros não muito.

Embora tenhamos percebido um esforço dos professores para o desenvolvimento da

\footnotetext{
23 Segundo EM1, Ciências da formação é a denominação para um elemento do curso que inclui ciência da educação, psicologia, sobre tudo psicologia da pedagogia, sociologia da formação e, às vezes, politologia e filosofia. Educação em Revista|Belo Horizonte|v.36|e231370|2020
} 
consciência social nesses módulos de estudos, podemos dizer que a demanda das competências, o estudo de módulos fechados, a prática de aulas em auditório e o enfoque das ciências da formação tornaram a formação mais ordenada com pouco espaço para criação, interpretações, comunicações, reflexões críticas sobre o social, a cultura e a dimensão humana, ainda que isso não seja impedido.

Já o modelo dos cursos de formação do pedagogo no Brasil que analisamos, o qual busca formar o profissional para atuar nas diferentes modalidades com menor carga horária, com diversas disciplinas que nem sempre conversam com a prática docente, tem dificuldade de atender à complexidade da demanda dos anos primários. Apesar da formação do docente para os anos primários ser prioridade, os cursos não conseguem adentrar nos conteúdos fundamentais das didáticas e conteúdos específicos necessários ao ensino nas escolas (GATTI, 2010). Isso leva a repensar se a carga horária de formação desse professor devesse ser maior e mais definida e, talvez, se não seria o caso de criar outros cursos de graduação ou mesmo de pós-graduação Lato Sensu por modalidades específicas de ensino para que esses saberes pudessem ser melhor trabalhados, o que não impediria que algumas disciplinas fossem comuns na formação, como já acontecia em algumas universidades brasileiras antes da DNCP/2006. Além disso, considerando o enfoque na formação do docente dos anos primários, seria importante que os professores dos cursos tivessem algum tipo de especialização nessa área, evitando a desarticulação com a complexidade das demandas dessa etapa de ensino na escola. No entanto, a crise econômica brasileira não permite o investimento público necessário para implementar tais reformas, enquanto a situação da economia alemã permite o investimento necessário. Além disso, menos desigualdade na Alemanha, junto com a crença que privilegia uma sociedade regida pelos princípios do liberalismo, permite uma definição dos objetivos da educação e, portanto, da formação de professores que seria muito difícil num contexto, como no Brasil, de profunda desigualdade e falta de confiança nos preceitos do liberalismo econômico.

\section{CONSIDERAÇÕES FINAIS}

Refletimos nesse artigo, a partir de uma abordagem que recorre à pesquisa de estudo comparado, realizada em 2017, na perspectiva da hermenêutica reconstrutiva, sobre instituições formativas brasileiras e alemãs. Considerando a intenção de proceder uma comparação delimitada entre a formação do ponto de vista de sua regulação e execução em dois países, não é intenção da pesquisa derivar reflexões para outras realidades, mas permitir que haja processos de aprendizagem pela via comunicativa mediante aquilo que Habermas (1993, p. 129) nomeia como "argumento surpreendente". Embora sejam contextos bem diferentes, no que se refere às condições econômicas e sociais, não seria sem sentido dizer que as reformas feitas em ambos os contextos têm suas raízes no mesmo movimento econômico e político global em curso desde a década de 70, às vezes chamada de 'globalização'. Os efeitos desse processo são bem diferentes nos dois países, sem dúvida. Entretanto, tanto as condições socioeconômicas como as propostas para a educação se fundamentam numa economia global que ainda privilegia os países da Europa e América do Norte em detrimento dos países do América do Sul. Os imperativos do sistema econômico global exigem uma formação orientada principalmente para o mercado e, portanto, aos subsistemas econômico e administrativo analisados pelo Habermas na sua teoria da ação comunicativa. Esses imperativos resultaram em cursos de formação de professor, em ambos dos países, focados principalmente na formação profissional e técnica necessária para atender as demandas desses dois subsistemas. No entanto, há diferenças que valem a pena destacar.

Apesar das inúmeras dificuldades em relação à preparação técnica do profissional, os cursos brasileiros investigados parecem favorecer as funções formativa que caracterizam o enraizamento no mundo da vida, conforme apontado por Habermas (1993; 2012) como uma necessidade do desenvolvimento universitário. Foi possível identificar nos currículos dos cursos e nas falas dos entrevistados que existe a preocupação com a superação das desigualdades sociais, com a formação da consciência crítica, com a produção e a reprodução de saberes culturais, com a reflexão antropológica e sociológica da escola e direitos humanos. Para além do currículo fechado de disciplinas, eles oferecem espaços de pesquisa e de extensão aos estudantes, discussão e participação em práticas sociais e culturais. 
Mesmo seguindo o interesse na qualidade da profissionalização técnica, podemos dizer que nos cursos analisados da Alemanha a formação especializada é feita de forma mais extensa do que nos casos vistos no Brasil, provavelmente atendendo melhor ao sistema econômico, o que acaba contribuindo para haver maior investimento na educação. Contudo, nos cursos brasileiros aos quais tivemos acesso, o espaço para a reprodução do mundo da vida e crítica ao sistema, indispensável a uma vida mais humanizada, aparece com mais destaque. Esse achado não deixa de ser irônico, pois justamente no país em que a formação é, historicamente, mais voltada aos subsistemas seja o país que acabou desenvolvendo a ideia de uma universidade que promove a racionalização do mundo da vida. A despeito dos esforços dos intelectuais na Alemanha, inclusive o próprio Habermas, de criticar e lutar contra essa tendência, parece que a formação mais técnica está sendo consolidada naquele país. Esse dado não é surpreendente, já que a Europa está atrás de retomar a sua posição de destaque na economia do mercado globalizado. Outro dado relevante é a de que, no Brasil, um país que ainda mantém alta dependência econômica com a Europa, o espaço para contestação e reflexão sobre o mundo da vida seja ainda possível, apesar de não sabermos ainda por quanto tempo.

Em se tratando de uma formação universitária que precisa responder criticamente às demandas atuais (tanto sistêmicas como do mundo vivido), é imprescindível a ampliação dos espaços de diálogo entre as demandas da vida e da profissionalização especializada. A universidade atual não pode se esquivar de repensar os ditames do sistema econômico e administrativo, não podendo também, em contrapartida, se reduzir a um espaço de formação técnica, tendo em vista o seu compromisso histórico com a formação humana. Como diz Dalbosco (2015, p. 2),

acreditar que a educação profissional tecnicamente especializada, sem o amparo da formação cultural mais ampla (Bildung), seria suficiente para dar conta dos problemas típicos de uma sociedade plural e interconectada, é se recusar a ver a profundidade complexa que constitui as mais diversas formas da vida humana e social.

Não há dúvidas de que as diferenças entre realidades apresentadas são frutos do contexto social, cultural e econômico de cada país. No entanto, seria conveniente pensar em um curso de formação docente que conseguisse balancear a relação entre o atendimento às demandas do sistema econômico e administrativo e o mundo da vida, ainda mais no que se refere à formação de professores para o contato diário com crianças, considerando a necessidade da formação de consciências mais humanizadas diante da supremacia do mercado mundial.

O fato da universidade ter mudado em função das exigências dos subsistemas econômico e administrativo, e oferecer o compromisso com a profissionalização técnica, não significa que ela deva abandonar o seu vínculo reflexivo com a vida, com o social e com a cultura. É necessário sim que ela redefina e atualize seu o papel, permitindo que a formação de profissionais para a atuação na docência nos anos primários seja também comprometida com o outro, com a diversidade, com a vida social, cultural e humana. Para além das diferenças entre ambos os modelos, o importante é que a formação atenda ao surpreendente apelo da entrevistada EM1: "formem bem os professores", afinal "os alunos não podem fugir dos professores".

Diante da recente publicação das novas diretrizes para formação inicial de professores (2019) no Brasil, fortemente criticada pelos principais fóruns e entidades educacionais do país, cabe analisar o novo perfil traçado para esse professor. Pois a princípio, parece uma tentativa de adequação às tendências formativas internacionais voltadas ao desenvolvimento de competências favoráveis às perspectivas consideradas essenciais da sociedade do conhecimento e globalizada. Não há dúvidas de que a lógica das competências na formação do professor representa um grande retrocesso no campo da docência, visto que a perspectiva faz jus à centralidade do cariz instrumental da formação, já balizado na atual Base Nacional Comum Curricular (BNCC). Portanto, considerando que o retorno com força redobrada da pedagogia das competências para centro das políticas públicas da educação no país, a crítica direcionada aos projetos educacionais - baseados nos princípios dessa categoria instrumental permanece, cada vez, mais necessária para uma educação voltada à defesa da democracia, embora 
tenhamos clareza de que melhorias referentes às competências profissionais do pedagogo para atuação nos anos primários sejam imprescindíveis.

\section{REFERÊNCIAS}

BANNELL, Ralph Ings. Habermas e a Educação. $2^{a}$ ed. Belo Horizonte, Autêntica, 2013.

BARTLETT, Lesley; VAVRUS, Frances. Estudos de caso comparado. Educação \& Realidade, Porto Alegre, v. 42, n. 3, p. 899-920, jul./set. 2017.

BRASIL. Lei 9,394 de 20 de dezembro de 1996. Estabelece as Diretrizes e Bases da Educação Nacional. Diário Oficial da União. Brasília, DF, 23 Dez. 1996.

BRASIL. Conselho Nacional de Educação. Parecer CNE/CP 5, 13.12.2005. Brasília, 2005.

BRASIL. Conselho Nacional de Educação. Resolução CNE/CP 1 de 15 de maio de 2006.

BRASIL. Conselho Nacional de Educação. Resolução CNE/CP 2 de $1^{\circ}$ de julho de 2015.

BRASIL. Conselho Nacional de Educação. Resolução CNE/CP 2 de 20 de Dezembro de 2019.

BRASIL. Plano Nacional de educação. Planejando a Próxima Década Conhecendo as 20 Metas do Plano Nacional de Educação. 2014.

BRZEZINSKI, Iria. Pedagogia, pedagogos e formação de professores. 9. ed. Campinas: Papiros, 2013.

CUNHA, Luiz Antônio. Educação brasileira: projetos em disputa (Lula x FHC na campanha eleitoral), São Paulo: Cortez, 1995.

CUNHA, Luiz Antônio. Qual universidade? São Paulo: Cortez, 1989.

CUNHA, Luiz Antônio. A universidade reformada: o golpe de 1964 e a modernização do ensino superior, Rio de Janeiro: Francisco Alves, $1^{\mathrm{a}}$ edição 1988; $2^{\mathrm{a}}$ edição São Paulo: Editora da UNESP, 2007.

DALBOSCO, Cláudio Almir. Educação superior e os desafios da formação para a cidadania democrática. Avaliação: Campinas, v. 20, n. 1, p. 123-142, Mar. 2015.

DEVECHI, Catia Piccolo Viero; TREVISAN, Amarildo Luiz. Sobre a proximidade do senso comum das pesquisas qualitativas em educação: positividade ou simples decadência? Revista Brasileira de Educação, v. 15, n. 43, p. 148-161, 2010.

DEVECHI, Catia Piccolo Viero; TAUCHEN, Gionara; TREVISAN, Amarildo Luiz. A figura do outro na educação comparada: Uma perspectiva de aprendizagem comunicativa. Revista Brasileira de Educação, v. 23, p. 1-15, 2018.

DEVECHI, Catia Piccolo Viero; WELLER, Wivian. Formação para a docência nos anos iniciais na Alemanha. Educação em Revista, Belo Horizonte, v. 34, e191658, 2018. 
DÖBERT, Hans. Germany. In: Hörner, W., Döbert, H., Reuter, L.R., von Kopp, B. (Eds.). The Education Systems of Europe. Second Edition. Cham (Switzerland) et al.: Springer, 2015, p. 305-333.

FRANCO, Maria Amélia Santoro; LIBÂNEO, José Carlos; PIMENTA, Selma Garrido. Elementos para a formulação de diretrizes curriculares para cursos de pedagogia. Cadernos de Pesquisa, v. 37, n. 130, jan/br. 2007.

FLICKINGER, Hans-Georg. Na contramão das atuais correntes pedagógicas. Cadernos de Pesquisa: Pensamento Educacional, Curitiba, v. 9, n. 22, p. 43-64, maio/ago. 2014.

GARCIA, Maria Manuela Alves. Políticas curriculares e profissionalização: saberes da prática na formação inicial de professores. Educação em Revista, Belo Horizonte, v. 32, n. 2, abr./jun. 2016.

GATTI, Bernadete. Formação de professores no Brasil: características e problemas. Educação e Sociedade, Campinas, v. 31, n. 113, p. 1355-1379, out./dez. 2010.

GRUSCHKA, Andreas. Adeus Pedagogia? O fim das fronteiras da relação pedagógica e a perda da função da pedagogia. In: LASTÓRIA, Luiz Antônio C. N.; ZUIN, Antônio A. S; GOMES, Luiz Roberto; GRUSCHKA, Andreas. Teoria Crítica: escritos sobre educação. Contribuições do Brasil e da Alemanha. São Paulo: Nankin, 2015.

HABERMAS, Jürgen. (Org.) Stichworte zur “Geistigen Situation der Zeit”. Suhrkamp Verlag; Erstausgabe Auflag, 1979.

HABERMAS, Jürgen. Further reflections on the public sphere. In: CRONIN, Ciaran; De GRIEFF (Org.) Habermas and the Public Sphere. Cambridge. Mass. MIT Press, 1992.

HABERMAS, Jürgen. A ideia de universidade: processos de aprendizagem. Revista Brasileira de Estudos Pedagógicos, Brasília, v. 74, p. 111-130, jan./abr. 1993.

HABERMAS, Jürgen. Direito e democracia: entre facticidade e validade. Rio de Janeiro: Tempo Brasileiro, 1997.

HABERMAS, Jürgen. A constelação pós-nacional. São Paulo: Littera Mundi, 2001.

HABERMAS, Jürgen. Mudança estrutural da esfera pública. $2^{\mathrm{a}}$ ed. Rio de Janeiro: Tempo Brasileiro, 2003.

HABERMAS, Jürgen. A inclusão do outro. São Paulo: Edições Loyola, 2004.

HABERMAS, Jürgen. Teoria do agir comunicativo. 2 volumes, São Paulo: Martins Fontes, 2012.

HAASLER, Simone R. The German system of vocational education and training: challenges of gender, academisation and the integration of low-achieving youth. In: Transfer 26 (1), p. 57-71, 2020.

HILLIGUS, Annegret Helen. Structural features and particularities of initial teacher education in germany: the specific role of universities. In: KUHLEE, Dina; VAN BUER, Jürgen; WINCH, Christopher (org.). Governance in initial teacher education: perspectives on England and Germany. Wiesbaden: Springer, 2015, p. 113-130. 
KANT, Immanuel. Resposta à pergunta: O que é esclarecimento. In: Kant et al. O que é

Esclarecimento. Rio de Janeiro, Viaverita, 2011.

KMK - Kultusministerkonferenz. Ländergemeinsame inhaltliche Anforderungen für die

Fachwissenschaften und Fachdidaktiken in der Lehrerbildung Deutschland (Beschluss der Kultusministerkonferenz vom 16.10.2008 i. d. F. vom 16.03.2017). Disponível em:

http://www.kmk.org/fileadmin/Dateien/veroeffentlichungen_beschluesse/2008/2008_10_16-

Fachprofile-Lehrerbildung.pdf. Acesso em: 17 jun. 2017.

KMK - Kultusministerkonferenz. Standards für die Lehrerbildung: Bildungswissenschaften. Beschluss der Kultusministerkonferenz vom 16.12.2004. Disponível em:

https://www.kmk.org/fileadmin/Dateien/veroeffentlichungen_beschluesse/2004/2004_12_16Standards-Lehrerbildung.pdf. Acesso em: 17 abr. 2017.

LIBÂNEO, José Carlos. Pedagogia e pedagogos: para que? São Paulo: Cortez, 2013.

MERKENS, Hans (org.). Lehrerbildung: Zentren für Lehrerbildung. Wiesbaden: VS Verlag für Sozialwissenschaften, 2005.

NRW - NORDRHEIN-WESTFALEN. Ministerium für Schule und Weiterbildung des Landes Nordrhein-Westfalen. Lehramtszugangsverordnung - LZV (Vom 25. April 2016). Disponível em: Https://recht.nrw.de/lmi/owa/br_vbl_detail_text?anw_nr=6\&vd_id=15620\&ver=8\&val=15620\&sg= 0\&menu=1\&vd_back=N. Acesso em: 17 abr. 2017.

NRW - NORDRHEIN-WESTFALEN. Ministerium für Schule... Lehrerausbildungsgesetz - LABG (Vom 12. Mai 2009 zuletzt geändert durch Gesetz vom 14. Juni 2016). Disponível em: https://www.schulministerium.nrw.de/docs/Recht/LAusbildung/LABG/LABGNeu.pdf. Acesso em: 17 jun. 2017.

NUSSBAUM, Martha. Sem fins lucrativos: por que a democracia precisa das humanidades. São Paulo: Martins Fontes, 2015.

OLIVEIRA, Nythamar. Processo de aprendizagem, mundo da vida e sistema: a ideia de universidade em Habermas. In: ROHDEN, Valério. Ideias de Universidade. Canoas: Ed. Ulbra, 2002.

ROBERTSON, Susan. L. The Bologna Process Goes Global: A Model, Market, Mobility, Brain Power or State-Building Strategy? An invitational paper to ANPED's Annual Conference, Caxambu, Minas Gerais, Brazil, 2008

ROBERTSON, Susan. L. Metaphoric Imaginings: Re/Visions on the Idea of a University, In: Rethinking the University After Bologna: New Concepts and Practices beyond Tradition and the Market: UCSIA, Antwerp, 2009a.

ROBERTSON, Susan L. 'Producing' the Global Knowledge Economy: the World Bank, the KAM, Education and Development. In: M. Simons, M. Olssen; M. Peters (org) Re-reading Education Policies: Studying the Policy Agenda of the $21^{\text {st }}$ Century, Rotterdam: Sense Publishers, 2009b.

ROBERTSON, Susan L. Challenges Facing Universities in a globalising world. Paper presented to the International Seminar on Quality in Higher Education: Indicators and Challenges, Pontifical Catholic University of Rio Grande do Sul (PUCRS), Brazil, 2010. 
SAVIANI, Dermeval. A pedagogia no Brasil: história e teoria. 2 ed. Campinas: Autores Associados, 2012.

WELLER, Wivian; ZARDO, Sinara. Entrevista narrativa com especialistas: aportes metodológicos e exemplificação. Revista da FAEEBA - Educação e Contemporaneidade, Salvador, v. 22, n. 40, p. 131-143, jul./dez., 2013.

Submetido: $23 / 11 / 2019$

Aprovado: $23 / 09 / 2020$

ERRATA

DOI: http://dx.doi.org/10.1590/0102-4698231370er

Para o artigo publicado como:

VIERODEVECHI, CATIA PICCOLO, BANNELL, RALPH INGS, \& TREVISAN, AMARILDO LUIZ. (2020). A FORMAÇÃO DO DOCENTE PARA OS ANOS PRIMÁRIOS EM CURSOS UNIVERSITÁRIOS NO BRASIL E NA ALEMANHA. Educação em Revista, 36, e231370. Epub 30 de novembro de 2020.https://doi.org/10.1590/0102$\underline{4698231370}$

O sobrenome da primeira autora fica alterado para DEVECHI

Onde se lê

\section{CATIA PICCOLO VIERODEVECHI}

Leia-se

CATIA PICCOLO VIERO DEVECHI 